\title{
Pituitary-adrenal influences on the acquisition of excitatory and inhibitory conditioned responses in rats
}

\author{
A. RANDICH, I. M. SMITH, and V. M. LoLORDO \\ Dalhousie University, Halifax, Nova Scotia, Canada
}

\begin{abstract}
In Experiment 1, groups of hypophysectomized, adrenal demedullated, adrenalectomized, and sham-operated rats received either no preexposure treatment or preexposure to unsignaled electric shock. All groups then received CER conditioning in which a 3-min white noise stimulus was repeatedly paired with an electric shock UCS. Among the groups in the nopreexposure condition, only adrenalectomized rats showed retarded acquisition of the CER. All the groups preexposed to electric shock acquired the CER at the same rate, but when compared to their no-preexposure counterparts showed attenuation of CER conditioning. These findings indicated that the hormones of the pituitary-adrenal system are not important for the UCS preexposure phenomenon obtained with CER conditioning. Experiment 2 examined the rate of acquisition of an inhibitory conditioned response in hypophysectomized, adrenal demedullated, adrenalectomized, and sham-operated rats. Hypophysectomy, and to a lesser degree adrenalectomy, impaired the acquisition of an inhibitory condition response relative to sham-operated controls and adrenal demedullated rats. These findings were discussed in terms of pituitary-adrenal influences on avoidance learning in rats.
\end{abstract}

Exposure to an aversive unconditioned stimulus (UCS) prior to pairings of a conditioned stimulus (CS) and the UCS generally attenuates the rate of acquisition of the excitatory conditioned response (CR). This attenuation effect, called the UCS preexposure phenomenon, has been demonstrated in a variety of Pavlovian conditioning paradigms including: (1) conditioning of the eyelid response in humans (Hobson, 1968; Kimble \& Dufort, 1956; Taylor, 1956) and the nictitating membrane response in rabbits (Mis \& Moore, 1973; Siegel \& Domjan, 1971), (2) conditioned suppression of food-reinforced responding in rats (Brimer \& Kamin, 1963; Kamin, 1961; Rescorla, 1973), and (3) conditioned taste aversion learning in rats (Cannon, Berman, Baker, \& Atkinson, 1975; Riley, Jacobs, \& LoLordo, 1976).

The nature of the deficit produced by prior exposure to the UCS has often been explained in nonassociative terms (Kamin, 1961; Mis \& Moore, 1973; Taylor, 1956). The most widely accepted nonassociative account of the UCS preexposure phenomenon argues that some "central" habituation or tolerance process (depending on the type of UCS) occurs in

Portions of this research were supported by Grant A-9585 from the National Research Council of Canada. Reprints may be obtained from A. Randich, Department of Psychology, Box 11A, Yale University, New Haven, Connecticut 06530. I. M. Smith is presently at Brown University. We wish to thank F. Baker and M. Yoon for their generous assistance in histological analyses, and F. R. Brush and J. C. Froehlich for comments on an earlier version of this manuscript. response to repeated presentations of the UCS during the preexposure phase. This reduces the organism's emotional responsiveness to subsequent applications of the UCS during excitatory conditioning, resulting in retarded acquisition of the excitatory CR.

Riley et al. (1976) suggested that the pituitaryadrenal system may serve as the substrate for this habituation process, and thereby mediate the UCS preexposure phenomenon. This hypothesis was based upon the following results. First, a variety of drugs and aversive stimuli that initially elicit a large adrenocorticotrophic hormone (ACTH) response elicit a relatively smaller ACTH response after they have been presented repeatedly (Bassett, Cairncross, \& King, 1973; Milulaj \& Mitro, 1972; Munson, 1973). Second, normal release of ACTH is important for the acquisition of active and passive avoidance responses, presumably via its action on increasing arousal or emotionality (Weiss, McEwen, Silva, \& Kalkut, 1969). Therefore, Riley et al. (1976) suggested the possibility that inhibition of stress-induced release of ACTH by prior exposure to the UCS may functionally act to attenuate the normal rate of acquisition of an excitatory CR, much as the lack of ACTH produced by hypophysectomy interferes with the normal acquisition of active and passive avoidance responses (cf. DeWied, 1964).

Braveman (Note 1) advanced an associative explanation of the UCS preexposure phenomenon which also involves the hormones of the pituitary-adrenal system. He proposed that, during extensive preexposure to the UCS, an adrenocortical response is con- 
ditioned to environmental stimuli. These environmental stimuli come to elicit adrenocortical activity, e.g., corticosterone release, which may reduce the aversiveness of a UCS that is paired with a discrete CS during the excitatory conditioning phase. This might also result in a retarded rate of excitatory conditioning.

The hypotheses of both Riley et al. (1976) and Braveman (Note 1) are based upon the view that ACTH acts to increase arousal or emotionality, resulting in greater generalized fear in aversive conditioning situations, whereas corticosterone counteracts the effect of ACTH by restoring normal levels of behavioral arousal (Weiss et al., 1969; Weiss, McEwen, Silva, \& Kalkut, 1970). This theory of pituitary-adrenal influences on aversively motivated behaviors is derived primarily from studies involving active and passive avoidance learning. At the present time, it is not known whether this view has sufficient generality to account for pituitary-adrenal influences on aversively motivated behaviors other than avoidance learning, and indeed, whether there is any justification for postulating a role for the hormones of the pituitary-adrenal system in the UCS preexposure phenomenon.

\section{EXPERIMENT 1}

Experiment 1 addresses these issues by asking two questions. Do rats with altered pituitary-adrenal function resulting from hypophysectomy, adrenalectomy, or adrenal demedullation show (1) normal acquisition of a conditioned emotional response (CER; Estes \& Skinner, 1941) established by pairing a discrete CS with an electric shock UCS, and (2) attenuated acquisition of a CER following prior exposure to an electric shock UCS?

\section{Subjects}

\section{Method}

Fifty-six male Sprague-Dawley rats obtained from Hormone Assay Laboratories in Chicago served as subjects. Rats weighed approximately $225 \mathrm{~g}$ at the start of the experiment and were individually housed in wire-mesh cages. The lights in the colony room were illuminated at $0600 \mathrm{~h}$ and turned off at $2000 \mathrm{~h}$. All surgical operations were performed by the vendors.

Adrenalectomized rats $(\mathrm{N}=14)$ had a $.9 \% \mathrm{NaCl}$ solution available in the home cage throughout the course of experimentation. Adrenal demedullated rats $(\mathrm{N}=14)$ had a $.9 \% \mathrm{NaCl}$ solution available in the home cage for 47 postoperative recovery days to allow for functional recovery of the adrenal cortex. Tap water was substituted for the $.9 \% \mathrm{NaCl}$ solution for the remainder of the postoperative recovery period (Days 47-64) and during the ensuing experiments. Hypophysectomized rats $(N=14)$ had a solution of $10 \%$ sucrose by weight available in the home cage throughout all experimentation. Sham-operated control rats $(\mathbf{N}=$ 14) had tap water available in the home cage throughout the course of experimentation.

\section{Apparatus}

Seven operant conditioning chambers $(22 \times 28 \times 19 \mathrm{~cm})$ enclosed in sound-attenuating wooden chests were used. The response lever was located $7.5 \mathrm{~cm}$ above a grid floor and $4.5 \mathrm{~cm}$ to the right of a centrally located food magazine. Grason-Stadler E104GS shock generators produced a nominal .8-mA electric shock delivered through the grid floor. The auditory stimulus was an 80-dB (scale A; $20 \mu \mathrm{N} / \mathrm{m}^{2}$ ) white-noise stimulus. Noyes food pellets $(45 \mathrm{mg}$ ) served as reinforcers.

\section{Procedure}

Postoperative recovery. All rats were allowed a 64-day postoperative recovery period upon their arrival in the laboratory (Buckingham \& Hodges, 1974). Food deprivation was instituted gradually, and rats were reduced to $85 \%$ of their free-feeding weights.

Baseline training. All experimental sessions were $1 \mathrm{~h}$ in duration, and a single session was given per day. All rats were initially shaped to depress the response lever to obtain food reinforcement on a fixed ratio 1 (FR 1) schedule. Following two sessions of FR 1 training, all groups were placed on a variable interval $30-\mathrm{sec}$ (VI 30-sec) schedule for two sessions, and then on a VI 1-min schedule for seven sessions.

Preexposure phase. The response levers were removed from the chambers, and the VI 1-min schedule was eliminated during the preexposure phase, i.e., preexposure was off-baseline.

Half the hypophysectomized, adrenalectomized, adrenal demedullated, and sham-operated rats were preexposed to unsignaled .8-mA electric shocks for 10 consecutive daily sessions. Two .5 -sec shocks were presented on a variable time (VT) basis during each daily 1-h session. Thus, these groups received a total of 20 .8-mA electric shocks over the course of 10 days.

The remaining rats were simply placed in the operant chambers during each of the 10 preexposure sessions, but received no exposure to electric shock.

CER conditioning. The response levers and the VI 1-min schedule of reinforcement were reinstated during conditioning of an emotional response. Commencing $24 \mathrm{~h}$ after the last preexposure session, all groups received signal-shock pairings superimposed on the VI 1-min schedule of reinforcement. Two CER trials were presented on a variable time basis during each daily session. These trials consisted of a 3-min white-noise stimulus which terminated with a .8-mA, .5-sec electric shock. Four days of CER conditioning were administered.

Sham-operated controls and adrenal demedullated rats were always tested between 0700 and $1100 \mathrm{~h}$; adrenalectomized rats were tested between 1100 and $1300 \mathrm{~h}$; and hypophysectomized rats were tested between 1300 and $1500 \mathrm{~h}$.

\section{Histology}

Hypophysectomized, adrenal demedullated, and sham-operated rats were sacrificed at the end of Experiment 2 . The adrenal glands were removed, cleaned, and weighed. The glands were then fixed in formal-saline, embedded in paraffin, and sectioned at $12 \mu$ prior to mounting and staining with haemotoxylin and eosin. Sections were examined microscopically for evidence of adrenal cortex regeneration in adrenal demedullated rats, adrenal atrophy in hypophysectomized rats, and normal structure in shamoperated rats. Hypophysectomy was also confirmed by gross inspection of the sella turcica and by analysis of body-weight gain. Adrenalectomy was confirmed by maintaining the putatively adrenalectomized rats on a salt-free diet. All adrenalectomized rats used in these experiments died within 14 days after removal of salt from their diet.

\section{Data Analysis}

Suppression ratios (Annau \& Kamin, 1961) were calculated as $B /(A+B)$, where $A$ represents the number of responses emitted during the 3-min period immediately preceding the CS, and B represents the number of responses emitted during the 3-min CS period.

Analyses of variance were performed on suppression ratios obtained on each CER trial. When the overall null hypothesis was rejected and further analysis was required, a set of $\mathrm{V}_{1}=\mathrm{J}-1$ mutually orthogonal post hoc contrasts of the form 
Table 1

Mean Body-Weight Gains (64 Days), Mean Adrenal Weights, Mean Rate of Responding on the VI 1-Min Schedule of Reinforcement, and Standard Errors of These Means

\begin{tabular}{|c|c|c|c|c|c|c|c|c|}
\hline \multirow[b]{3}{*}{ Group } & \multirow{2}{*}{\multicolumn{2}{|c|}{ Mean Body-Weight Gain }} & \multirow{2}{*}{\multicolumn{2}{|c|}{ Mean Adrenal Weight }} & \multicolumn{4}{|c|}{ Mean Response Rates } \\
\hline & & & & & \multicolumn{2}{|c|}{ No Preexposure } & \multicolumn{2}{|c|}{ Preexposure } \\
\hline & Mean & SE & Mean & SE & Mean & $\mathrm{SE}$ & Mean & $\mathrm{SE}$ \\
\hline Sham Operated & 163.60 & 5.28 & 34.90 & 2.83 & 21.79 & 1.04 & 24.14 & 1.08 \\
\hline Adrenalectomized & 139.70 & 14.12 & & & 18.12 & 1.04 & 29.05 & 1.47 \\
\hline Hypophysectomized & -7.00 & 2.71 & 6.50 & .38 & 5.76 & .20 & 10.35 & .43 \\
\hline Adrenal Demedullated & 152.30 & 6.80 & 33.10 & 4.09 & 19.79 & .60 & 29.78 & 1.93 \\
\hline
\end{tabular}

Note-Mean body-weight gains are given in grams, mean adrenal weights in milligrams, and mean response rates in responses per minute.

$$
\sum_{j}=c_{j} m_{j}
$$

where $\Sigma c_{j}=0$ and $m_{j}$ are sample means, were sought. Such contrasts are weighted combinations of the means in which the coefficient $c_{j}$ is the weight given to the $j^{\text {th }}$ mean $m_{j}$. The critical value for rejecting the null contrast was obtained from Rodger's (1975) tables of $F\left(E_{\alpha}\right) ; V_{1}, V_{2}$. The use of $F(.05) ; V_{1}, V_{2}$ insured that the proportion of null contrasts rejected in error will be $\mathrm{E}_{\alpha}$ when all null contrasts are true.

\section{Results}

Table 1 presents mean body-weight gain over the 64-day recovery period, mean adrenal weights, and mean rates of responding on the VI 1-min schedule during the CER conditioning phase. For purposes of adrenal-weight and body weight-gain comparisons, data from rats receiving a given surgical operation were combined regardless of their preexposure treatment, and compared with similar combinations in the other surgical categories.

An analysis of variance on mean body-weight gain over the 64-day recovery period yielded a significant between-groups effect $[F(3,52)=91.04]$. Inspection of Table 1 indicates that this effect was primarily due to a mean body-weight loss of $7.00 \mathrm{~g}$ in hypophysectomized rats. An analysis of variance on adrenal weights yielded a significant between-groups effect $[F(2,39)=30.62]$. Adrenal weights of sham-operated and adrenal demedullated rats were approximately equal, and much greater than those of hypophysectomized rats.

An analysis of variance on the rates of responding maintained by the VI 1-min schedule of reinforcement during CER conditioning yielded significant differences among no-preexposure groups $[\mathrm{F}(3,24)=7.05]$ and among groups preexposed to shock $[F(3,24)=$ 6.81]. Inspection of Table 1 indicates that these differences were due to low rates of responding in hypophysectomized rats. Although response rates were low in hypophysectomized rats, these values remained stable over CER conditioning, varying by less than $.85 \mathrm{rsp} / \mathrm{min}$ from day to day.

Figure 1 presents mean trial-by-trial suppression ratios for the various groups over the 4 days of CER conditioning. The functions depicted in the upper panel are for no-preexposure treatment groups, and those in the lower panel are for groups preexposed to electric shock.

The upper panel of Figure 1 shows that among the groups receiving no preexposure treatment, adrenalectomized rats acquired the CER at a slower rate than sham-operated, hypophysectomized, and adrenal demedullated rats. One-way analyses of variance on trial suppression ratios yielded significant betweengroups differences on Trials 1, 3, 4, and 5 (Fs range from 2.85 to 7.95). Post hoc contrasts on the mean suppression ratios obtained on Trial 1 revealed that hypophysectomized rats showed significantly greater unconditioned suppression of responding to the novel white-noise stimulus than did sham-operated, adrenalectomized, and adrenal demedullated rats, which were equivalent. However, the response to the whitenoise stimulus in hypophysectomized rats was like that of the other groups on Trial 2. In post hoc

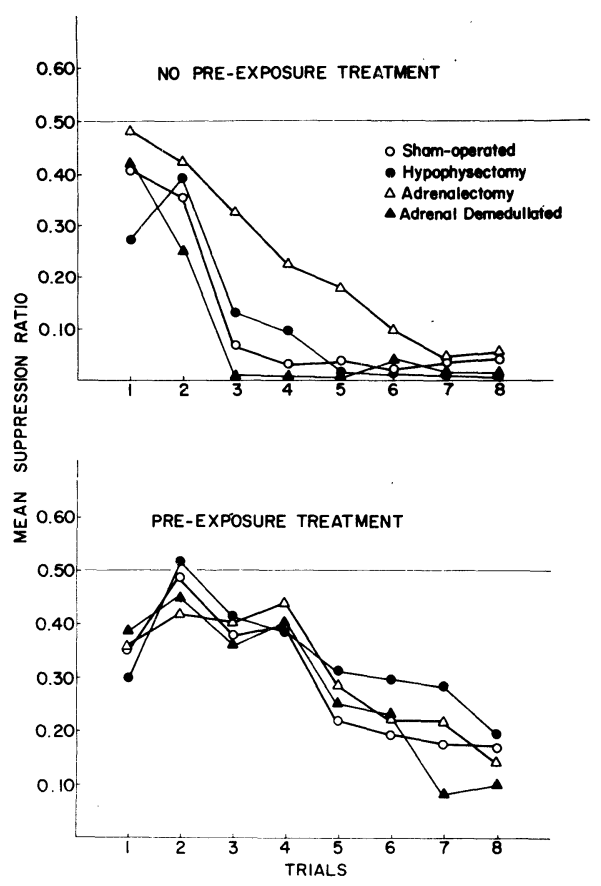

Figure 1. Mean trial-by-trial suppression ratios for groups receiving no preexposure treatment (upper panel) and groups receiving prior exposure to electric shock (lower panel). 
analyses of mean suppression ratios obtained on Trials 3, 4, and 5, adrenalectomized rats showed significantly less conditioned suppression of responding than did sham-operated, hypophysectomized, and adrenal demedullated rats, which were equivalent. Thus, adrenalectomized rats acquired the CER at a slower rate than the other groups, but attained the same asymptotic level of conditioned suppression by Trial 6.

The lower panel of Figure 1 shows that all groups preexposed to electric shock acquired the CER at approximately the same rate, and there were no significant between-groups differences. Additional split-plot analyses of variance comparing suppression ratios for groups given prior exposure to shock with those of groups given no prior exposure to shock indicated that prior exposure to shock attenuated the acquisition of a CER. A significant effect of the preexposure treatment was obtained between shamoperated groups $[F(1,12)=19.42]$, hypophysectomized groups $[\mathrm{F}(1,12)=26.93]$, and adrenal demedullated groups $[\mathrm{F}(1,12)=25.52]$, but not between adrenalectomized groups $[F(1,12)=2.06]$. The failure to obtain a decremental effect of prior exposure to shock in the adrenalectomized rats clearly stems from the significant retardation of CER acquisition obtained in adrenalectomized rats not preexposed to shock.

\section{Discussion}

Experiment 1 evaluated whether the hormones of the pituitary-adrenal system influence the acquisition of a CER, and sought to determine whether this system mediates the UCS preexposure phenomenon.

In regard to the first goal, only adrenalectomized rats showed impaired acquisition of a CER among the groups in the no preexposure condition. Adrenalectomy eliminates the endogenous source of glucocorticoids, and results in high circulating levels of ACTH (Usategui, Oliver, Vaudry, Lombardi, Rosenberg, \& Mourre, 1976) and an exaggerated release of ACTH in response to stress (Dallman \& Jones, 1973). It is reasonable to assume that the decremental effect of adrenalectomy on the acquisition of a CER stems from high circulating levels of ACTH and/or an exaggerated release of ACTH in response to stress, since hypophysectomized rats, which lack functional glucocorticoid release, showed normal acquisition of the CER.

Second, there was no evidence to support the speculation of Riley et al. (1976) that inhibition of stressinduced release of $\mathrm{ACTH}$, resulting from prior exposure to the UCS, mediates the UCS preexposure phenomenon. This view predicts that hypophysectomized rats receiving no preexposure treatment would show retarded acquisition of a CER relative to shamoperated rats because hypophysectomized rats are incapable of release of ACTH. Hypophysectomized rats in the present experiment acquired the CER as rapidly as sham-operated controls. Moreover, hypophysectomized rats preexposed to electric shock showed attenuation of CER conditioning relative to hypophysectomized rats not preexposed to shock, again indicating that the USC preexposure phenomenorı is independent of the action of ACTH.

The results of this experiment also suggest that Braveman's (Note 1) view of the UCS preexposure phenomenon is incorrect. He suggested that an adrenocortical response is conditioned to environmental stimuli during preexposure to the UCS. Further, he maintained that the adrenocortical response elicited by environmental stimuli may reduce the aversiveness of the UCS paired with a discrete CS during subsequent excitatory conditioning in that environment. This explanation is unlikely to be correct for the UCS preexposure phenomenon obtained with CER conditioning, because hypophysectomized rats preexposed to shock were slower to acquire a CER than were nonpreexposed hypophysectomized rats. A hypophysectomized rat is incapable of acquiring a conditioned adrenocortical response to environmental stimuli, or to a discrete CS.

However, hypophysectomized rats in the present experiment had significantly lower rates of responding on the VI 1-min schedule of reinforcement than did the other groups. It is known that the magnitude of conditioned suppression of responding is influenced by the baseline rate of responding. Blackman (1968) has shown that when reinforcement frequency is held constant, as was the case in the present experiment, rats with high baseline rates of responding tend to show more conditioned suppression of responding than do rats with low baseline rates of responding. Thus, it can be argued that the hypophysectomized rats, which had low baseline rates of responding, should have acquired conditioned suppression more slowly than the other groups. That they did not so do strengthens the argument that the views proposed by Riley et al. (1976) and Braveman (Note 1) cannot be applied to the CER procedure.

\section{EXPERIMENT 2}

Weiss et al. (1969) proposed that ACTH acts to increase arousal or emotionality, resulting in greater generalized fear in aversive conditioning situations, whereas corticosterone counteracts the effect of ACTH by restoring normal levels of behavioral arousal. In a functionally similar theory, Levine (1968) proposed that glucocorticoids facilitate the development of internal inhibition (Pavlov, 1927) and that ACTH acts to disinhibit internal inhibition. The results of studies of the influence of the pituitary-adrenal system on avoidance learning support such views. Elimination of ACTH by hypophysectomy impairs the acquisition of active and passive avoidance responses (Applezweig \& Baudry, 1955; DeWeid, 1964; 
Lissák \& Bohus, 1972), and exogenous administration of ACTH prolongs avoidance responding during extinction testing (DeWeid, 1966, 1974; Levine \& Jones, 1965; Murphy \& Miller, 1955).

However, the results of the CER conditioning procedure in Experiment 1 did not support the general implications of either of these theories of pituitaryadrenal function. Hypophysectomized rats did not show attenuated acquisition of a CER, whereas adrenalectomized rats did show impaired acquisition of a CER. Such findings not only question the generality of these views, but raise the question of: What aspect of avoidance behavior is impaired by the lack of ACTH, if not conditioning of a fear response to a warning signal? In this regard, two-factor theory of avoidance learning (Mowrer, 1947; Solomon \& Brush, 1956) argues that conditioning of a fear response to a discrete CS is only the first process which occurs during the acquisition of an avoidance response. It is possible, therefore, that hypophysectomy impairs some other process which is necessary for successful avoidance behavior. Perhaps that is the second process of two-factory theory of avoidance learning, the process that reinforces the instrumental avoidance response itself. This second process involves negative reinforcement of the instrumental avoidance response by diminution of fear elicited by the warning signal, as well as positive reinforcement of the avoidance response by response-produced and other stimuli which are explicitly unpaired with the aversive UCS, i.e., conditioned inhibitors of fear (Rescorla, 1969).

Experiment 2 addresses this issue by examining the rate of acquisition of an inhibitory conditioned response in rats which have sustained hypophysectomy, adrenalectomy, or adrenal demedullation. The conditioned inhibition procedure (Pavlov, 1927) was chosen because it permits trial-by-trial assessment of the formation of an inhibitory conditioned response.

\section{Subjects}

\section{Method}

The 28 rats which served in the various no-preexposure conditions of Experiment 1 served as subjects in Experiment 2. All other conditions were as described in Experiment 1.

\section{Apparatus}

The visual stimulus which served as one element of the compound CS-stimulus in this experiment was a white houselight, which projected through a white, Perspex ceiling $\left(1.92 \mathrm{~cd} / \mathrm{m}^{2}\right)$. All other apparatus were as described in Experiment 1 .

\section{Procedure}

Groups in the no-preexposure conditions of Experiment 1 began the conditioned inhibition phase of the experiment $24 \mathrm{~h}$ after the last CER trial of Experiment 1. On each of 8 consecutive days, all groups received one 3-min white-noise stimulus paired with a .8-mA electric shock (CS + trial), and one 3-min compound stimulus, composed of white noise and light, which was not reinforced (CS - trial). The presentation of CS + and CS - trials during the 8 days of conditioned inhibition training occurred in an ABBA sequence. As in Experiment 1, all $\mathrm{CS}+$ and $\mathrm{CS}-$ trials were superimposed on the VI 1-min schedule of reinforcement.

\section{Results}

The histological verification of surgical procedures was presented in Experiment 1. The mean rates of responding on the VI 1-min baseline for various groups during conditioned inhibition training were: sham controls $=24.45$; adrenalectomized $=22.49$; adrenal demedullated $=21.70$; and hypophysectomized $=5.74 \mathrm{rsp} / \mathrm{min}$. A split-plot analysis of variance on mean response rates yielded a significant between-groups effect $[F(3,24)=9.37]$. This effect was primarily due to low rates of responding in hypophysectomized rats.

Figure 2 presents mean trial-by-trial suppression ratios for the various groups on CS- trials (upper panel) and CS + trials (lower panel).

The upper panel of Figure 2 shows that hypophysectomized rats and, to a lesser degree, adrenalectomized rats acquired the inhibitory conditioned response more slowly than either sham controls or adrenal demedullated rats. One-way analyses of variance performed on each CS - trial yielded significant between-groups differences on every trial except Trial 4 (Fs range from 2.38 to 8.10 ). Post hoc analyses of mean trial suppression ratios indicated that hypophysectomized rats showed significantly greater conditioned suppression of responding during these CS - trials than sham-operated and adrenal demedullated rats, which were equivalent. In addition, on Trials 5-8 of the conditioned inhibition procedure,

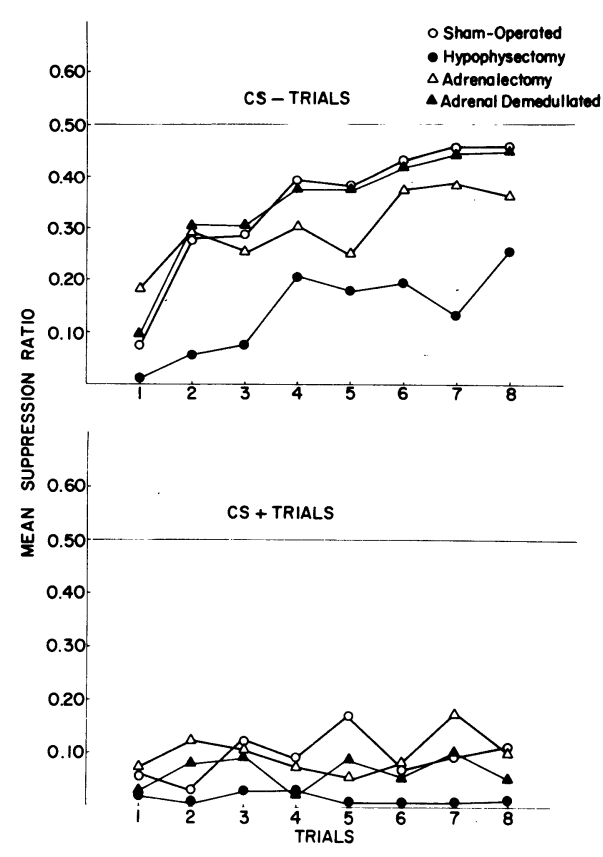

Figure 2. Mean trial-by-trial suppression ratios for groups during CS - or conditioned inhibition trials (upper panel), and during $\mathrm{CS}+$ or conditioned excitation trials (lower panel). 
adrenalectomized rats had implied population mean suppression ratios which were less than those of sham-operated and adrenal demedullated rats combined, and greater than those of hypophysectomized rats.

The lower panel of Figure 2 indicates that hypophysectomized rats also showed greater conditioned suppression of responding during $\mathrm{CS}+$ trials than the other groups. Significant between-groups differences were obtained on Trials 2, 5, and 7 (Fs range from 2.09 to 2.23). However, even when suppression ratios on CS + and CS - trials are analyzed using difference scores (Rescorla, 1971), the patterning of suppression ratios is virtually identical to that provided by the analysis of CS- trials alone.

\section{Discussion}

Hypophysectomized rats and, to a lesser degree, adrenalectomized rats acquired the inhibitory conditioned response at a slower rate than either shamoperated or adrenal demedullated rats. Other investigators (Henderson, 1978; Marchant, Mis, \& Moore, 1972; Rescorla \& Holland, 1977) have used summation and retardation of acquisition tests to verify that the procedure used here does result in the conditioning of inhibition to the CS- stimulus, rather than in some nonassociative effect, although such tests were not conducted in the present experiment.

These results suggest that hypophysectomized rats and adrenalectomized rats are impaired in their ability to inhibit a CER to a compound stimulus specifically unpaired with an electric shock UCS, where one of the elements of the compound $\mathrm{CS}-$ stimulus is the $\mathrm{CS}+$ stimulus. These findings lend partial support to the views of both Levine (1968) and Weiss et al. (1969) concerning the action of corticosterone in facilitating the development of inhibition, since both hypophysectomized and adrenalectomized rats, which lack corticosterone release, showed impaired acquisition of the inhibitory conditioned response. However, both positions predict that adrenalectomized rats should have shown more impairment than hypophysectomized rats. This result was not obtained. In Levine's (1968) view, for example, adrenalectomized rats should be impeded in developing internal inhibition because they lack corticosterone, but should be capable of disinhibiting any internal inhibition which may develop through the action of ACTH. Similar predictions, based upon the emotionality or arousal effects proposed to be elicited by ACTH and corticosterone, can be derived from the view of Weiss et al. (1969). Thus, while the aforementioned theories provide a reasonable explanation of pituitaryadrenal influences on avoidance learning, they do not appear to have sufficient generality to account for all of the influences of the pituitary-adrenal system on simple Pavlovian excitatory and inhibitory condi- tioning. However, as previously noted, the shortcomings of these theories appear to reflect an inadequate understanding of the role of $\mathrm{ACTH}$, rather than of corticosterone.

It is unlikely that the low baseline rates of responding in hypophysectomized rats resulted in the retarded acquisition of the inhibitory conditioned response. Low rates of responding would be expected to facilitate rather than impede the formation of an inhibitory conditioned response as measured by a CER procedure (Blackman, 1968).

\section{GENERAL DISCUSSION}

Experiment 1 provided important information regarding the role of the hormones of the pituitaryadrenal system in the acquisition of a CER. In the no-preexposure condition of Experiment 1, adrenalectomized rats acquired a CER at a slower rate than did sham-operated, hypophysectomized, and adrenal demedullated rats. The decremental effect of adrenalectomy on the acquisition of a CER was attributed to the high circulating levels of ACTH and/or the exaggerated release of ACTH in response to stress, both of which result from adrenalectomy. The lack of glucocorticoids resulting from adrenalectomy cannot account for this effect, since hypophysectomized rats, which lack functional glucocorticoid release, showed normal acquisition of the CER. Formally similar effects of high circulating levels of ACTH have been reported by Mirsky, Miller, and Stein (1953) in a conditioned punishment experiment with monkeys. In that experiment, monkeys which received ACTH and tone-shock pairings subsequently showed less disruption of food-reinforced responding when the tone stimulus was presented on a FR 1 schedule than did monkeys which had not received ACTH prior to the punishment procedure. In contrast, Weiss et al. (1969) reported that adrenalectomized rats acquired a CER at the same rate as sham-operated control rats. However, a high-intensity electric shock UCS was used in that study, and the authors noted that their UCS promoted very rapid conditioning of the emotional response, and hence may have minimized the opportunity to detect an effect of adrenalectomy. In the present study, which used a moderately intense electric shock UCS, adrenalectomized rats showed retarded acquisition of a CER for five trials, but then attained the same asymptotic level of conditioned suppression as shamoperated, hypophysectomized, and adrenal demedullated rats. This is a substantial retardation of conditioning in a CER paradigm.

Hypophysectomized rats in the no-preexposure condition of Experiment 1 showed normal acquisition of a CER. This result corroborates reports of both Davis, Green, Herrmann, and Levine (1978) and Weiss et al. (1969) that treatments which eliminate 
ACTH or inhibit ACTH release do not influence the acquisition of a CER. In the latter study, for example, intrahypothalamic implants of crystalline cortisol, a procedure which inhibited normal pituitaryadrenal function, did not affect the acquisition of a CER in rats. Thus, although high circulating levels of ACTH may retard the acquisition of a CER, the lack of ACTH appears to have no effect on the acquisition of a CER.

Adrenal demedullated rats also showed normal acquisition of a CER in the no-preexposure condition of Experiment 1 (cf. Leshner, Brookshire, \& Stewart, 1971). In contrast, Paré and Cullen (1971) reported that adrenal demedullated rats acquired a CER at a lower rate than did sham-operated controls. The differences in the length of the postoperative recovery periods given to adrenal demedullated rats in these studies may account for this discrepancy. In the study of Paré and Cullen (1971), a 12-day postoperative recovery period was provided, whereas in the present experiment, a 64-day postoperative recovery period was used. Buckingham and Hodges (1974) showed that functional recovery of the adrenal cortex following an adrenal demedullation procedure requires at least 64 days (cf. Shapiro \& Péron, 1973). It is possible, therefore, that the decremental effect of adrenal demedullation on acquisition of a CER reported by Paré and Cullen (1971) resulted from adrenal cortical damage. Such an interpretation would be compatible with the present finding that adrenalectomized rats showed retarded acquisition of a CER.

Experiment 1 also tested the views of Riley et al. (1976) and Braveman (Note 1) regarding the role of the hormones of the pituitary-adrenal system in the UCS preexposure phenomenon. Neither of these two views was supported by the results of this experiment. Rats sustaining hypophysectomy, adrenal demedullation, or a sham operation showed retarded acquisition of a CER following exposure to shock relative to their nonpreexposed counterparts. Only marginal attenuation of CER conditioning occurred in adrenalectomized rats preexposed to electric shock relative to adrenalectomized rats not preexposed to electric shock. However, this result was attributed to the retarded acquisition of the CER evidenced by the latter group, and was concluded to be an effect independent of that which produces the UCS preexposure phenomenon (see the discussion of Experiment 1). Thus, these results revealed yet another situation in which activation of the pituitary-adrenal system may be a reliable correlate of a behavior which occurs under stressful conditions, but is not a necessary condition for the occurrence of that behavior (Davis et al., 1978; Davis, Porter, Livingston, Herrmann, MacFadden, \& Levine, 1977).

Although Experiment 1 showed that hypophysectomized rats acquire a strong CER to a discrete CS paired with an electric shock UCS, Experiment 2 indicated that hypophysectomized rats do not readily inhibit that response to a compound stimulus specifically unpaired with an electric shock UCS, when one of the elements of the compound is the CS + . The nature of the deficit resulting from hypophysectomy which retards the acquisition of an inhibitory conditioned response is unclear. It may be that the hypophysectomized rat is impaired in inhibiting fear to a CS - stimulus, or that the hypophysectomized rat suffers some general impairment in its ability to discriminate the stimuli used on $\mathrm{CS}+$ and $\mathrm{CS}-$ trials. Furthermore, the decremental effect of hypophysectomy on the acquisition of an inhibitory conditioned response may reflect, not the lack of ACTH, but rather the absence of some other pituitary hormone eliminated by hypophysectomy. Regardless of these uncertainties, several aspects of the behavior exhibited by hypophysectomized rats in Experiment 2 are particularly noteworthy, and may have implications for the study of this preparation in avoidance paradigms.

First, Weiss et al. (1969) reported that hypophysectomized rats show faster extinction of a CER than sham-operated rats when extinction testing is conducted in a "novel" stimulus environment. During the course of a conditioned inhibition procedure, the CER elicited by the CS + stimulus should also extinguish to some extent by virtue of its nonreinforced presentations in the compound CS- stimulus (Rescorla \& Wagner, 1972). Hypophysectomized rats showed no loss of conditioned suppression to the $\mathrm{CS}+$ stimulus during conditioned inhibition training in the present study, whereas all the other groups did show some extinction of the CER to the CS + stimulus. Although the conditioned inhibition procedure was not conducted in a "novel" stimulus environment, one would expect hypophysectomized rats to show some extinction of the CER to the CS + stimulus. Thus, although hypophysectomized rats may show faster extinction of a CER in a "novel" stimulus environment, they show no tendency toward this behavior in a "familiar" stimulus environment. This strong suppression of responding by hypophysectomized rats during $\mathrm{CS}+$ trials of the conditioned inhibition procedure also poses a paradox for their behavior during $\mathrm{CS}$ - trials. In normal rats, the rate at which an inhibitory conditioned response is acquired is a direct function of the strength of the CER elicited by the CS + stimulus (Rescorla \& Wagner, 1972). However, if the CS + stimulus of the hypophysectomized rats elicited a stronger CER than in the other groups, it did not facilitate the acquisition of the inhibitory conditioned response.

Rescorla and LoLordo (1965) have argued that the conditioned inhibition procedure is a useful model of events which occur in the learning of an avoidance response. For example, when a warning signal occurs 
and there is no response, shock follows. This sequence of events is formally similar to CS + trials in a conditioned inhibition procedure. When the warning signal occurs and is accompanied by feedback stimuli produced by an avoidance response, no shock occurs. This sequence of events parallels CS - trials in a conditioned inhibition procedure. Thus, to the extent that fear reduction reinforces the avoidance response, a rat which is impaired in inhibiting fear to a CSstimulus would have difficulty acquiring the avoidance response. In this sense, one important source of reinforcement of the avoidance response, the conditioning of inhibition of fear to stimuli produced by the avoidance response, may be of little value to the hypophysectomized rat. This factor alone might account for the poor avoidance learning evidenced by the hypophysectomized rat. However, as noted previously, it remains to be determined whether the decremental effect of hypophysectomy on the acquisition of an inhibitory conditioned response reflects the lack of $\mathrm{ACTH}$, as does the decremental effect of hypophysectomy on the acquisition of an avoidance response.

\section{REFERENCE NOTE}

1. Braveman, N. S. Conditioned drug states and the treatment preexposure effect in taste aversion learning. Unpublished manuscript, 1977.

\section{REFERENCES}

Annau, Z., \& Kamin, L. J. The conditioned emotional response as a function of intensity of the US. Journal of Comparative and Physiological Psychology, 1961, 54, 428-432.

Applezweig, M. H., \& BAUdRY, F. D. The pituitaryadrenocortical system in avoidance learning. Psychological Reports, 1955, 1, 417-420.

Bassett, J. R., Cairncross, K. D., \& King, M. D. Parameters of novelty, shock predictability and response contingency in corticosterone release in the rat. Physiology \& Behavior, 1973, 10, 901-907.

Blackman, D. E. Response rate, reinforcement frequency, and conditioned suppression. Journal of the Experimental Analysis of Behavior, 1968, 11, 503-516.

BrImer, C. J., \& Kamin, L. J. Disinhibition, habituation, sensitization, and the conditioned emotional response. Journal of Comparative and Physiological Psychology, 1963, 56, 508-516.

Buckingham, J. C., \& Hodges, J. R. The redox bioassay technique for the direct assessment of pituitary adrenocorticotrophic activity. Clinical Endocrinology, 1974, 3, 347-348.

Cannon, D. S., Berman, R. F., Baker, T. B., \& Atkinson, C. A. Effect of preconditioning unconditioned stimulus experience on learned taste aversions. Journal of Experimental Psychology, 1975, 104, 270-284.

Dallman, M. F., \& Jones, M. T. Corticosteroid feedback control of ACTH secretion: Effect of stress-induced corticosterone secretion on subsequent stress responses in the rat. Endocrinology, 1973, 92, 1367-1375.

Davis, H., Green, B., Herrmann, R., \& Levine, S. Blockage of pituitary-adrenal activity does not affect conditioned suppression. Physiology \& Behavior, 1978, 20, 423-425.

Davis, H., Porter, J., Livingston, J., Herrmann, T., MacFadden, L., \& Levine, S. Pituitary-adrenal activity and leverpress shock escape behavior. Physiological Psychology, 1977, 5, 280-284.
DEWIED, D. Influence of the anterior pituitary on avoidance learning and escape behavior. American Journal of Physiology, 1964, 207, 255-259.

DEWIED, D. Inhibitory effects of ACTH and related peptides on extinction of conditioned avoidance behavior in rats. Proceedings of the Society for Experimental Biology and Medicine, 1966, 122, 28-32.

DEWIED, D. Pituitary-adrenal system hormones and behavior. In F. O. Schmitt \& F. G. Worden (Eds.), The neurosciences: Third study program. Cambridge, Mass: MIT Press, 1974.

Estes, W. K., \& Skinner, B. F. Some quantitative properties of anxiety. Journal of Experimental Psychology, 1941, 29, 390-400.

HENDERSEN, R. W. Forgetting of conditioned fear inhibition. Learning and Motivation, 1978, 9, 16-30.

Hobson, G. N. Effects of UCS adaptation upon conditioning in low and high anxiety men and women. Journal of Experimental Psychology, 1968, 76, 360-363.

KAmin, L. J. Apparent adaptation effects in the acquisition of a conditioned emotional response. Canadian Journal of Psychology, 1961, 15, 176-188.

Kimble, G. A., \& DuforT, R. H. The associative factor in eyelid conditioning. Journal of Experimental Psychology, 1956, 52, 386-391.

Leshner, A. I., Brookshire, K. H., \& Stewart, C. N. The effects of adrenal demedullation on conditioned fear. Hormones and Behavior, 1971, 2, 43-48.

LeVINE, S. Hormones and conditioning. In W. J. Arnold (Ed.), Nebraska Symposium on Motivation. Lincoln: University of Nebraska Press, 1968.

LeVINe, S., \& Jones, L. E. Adrenocorticotropic hormone (ACTH) and passive avoidance learning. Journal of Comparative and Physiological Psychology, 1965, 59, 357-360.

LISsÁk, K., \& BoHUs, B. Pituitary hormones and the avoidance behavior of the rat. International Journal of Psychobiology, 1972, 2, 103-115.

Marchant, H. G., Mis, F. W., \& Moore, J. W. Conditioned inhibition of the rabbit's nictitating membrane response. Journal of Experimental Psychology, 1972, 95, 408-411.

MilulaJ, L., \& Mitro, A. Endocrine functions during adaptation to stress. Advances in Experimental Medicine and Biology, 1972, 33, 631-638.

Mirsky, I. A., Miller, R., \& Stein, M. Relation of adrenocortical activity and adaptive behavior. Psychosomatic Medicine, 1953, 15, 574-584.

MIs, R. W., \& Moore, J. W. Effects of preacquisition UCS exposure on classical conditioning of the rabbit's nictitating membrane response. Learning and Motivation, 1973, 4, 108-114.

MOWRER, O. H. On the dual nature of learning: A reinterpretation of "conditioning" and "problem-solving." Harvard Educational Review, 1947, 17, 102-148.

Munson, P. L. Effects of morphine and related drugs on the corticotrophin (ACTH)-stress reaction. Progress in Brain Research, 1973, 39, 361-372.

Murphy, J. V., \& Miller, R. E. Effect of adrenocorticotrophic hormone (ACTH) on avoidance conditioning in the rat. Journal of Comparative and Physiological Psychology, 1955, 48, 47-49.

PARÉ, W. P., \& Cullen, J. W. Adrenal influences on the aversive threshold and CER acquisition. Hormones and Behavior, 1971, 2, 139-147.

Pavlov, I. P. Conditioned reflexes. London: Oxford, 1927. (Reprinted, New York: Dover, 1960.)

Rescorla, R. A. Pavlovian conditioned inhibition. Psychological Bulletin, 1969, 72, 77-94.

Rescorla, R. A. Summation and retardation tests of latent inhibition. Journal of Comparative and Physiological Psychology, 1971, 75, 77-81.

RESCORLA, R. A. Effect of US habituation following conditioning. Journal of Comparative and Physiological Psychology, 1973, 82. 137-143. 
Rescorla, R. A., \& Holland, P. C. Associations in Pavlovian conditioned inhibition. Learning and Motivation, 1977, 8, $429-447$.

Rescorla, R. A., \& Lolordo, V. M. Inhibition of avoidance behavior. Journal of Comparative and Physiological Psychology, 1965, 59, 406-412.

Rescorla, R. A., \& Wagner, A. R. A theory of Pavlovian conditioning: Variations in the effectiveness of reinforcement and nonreinforcement. In A. H. Black \& W. F. Prokasy (Eds.), Classical conditioning II: Current theory and research. New York: Appleton-Century-Crofts, 1972.

Riley, A. L., JAcobs, W. J., \& LoLordo, V. M. Drug exposure and the acquisition and retention of a conditioned taste aversion. Journal of Comparative and Physiological Psychology, 1976, 90, 799-807.

RODGER, R. S. The number of non-zero, post hoc contrasts from ANOVA and error rate. I. British Journal of Mathematical and Statistical Psychology, 1975, 28, 71-78.

Shapiro, B. H., \& PÉRon, F. G. Corticosteroid levels in adrenal cell suspension and plasma from normal and adrenal regenerating rats. Endocrinology, 1973, 92, 175-188.
Siegel, S., \& Domjan, M. Backward conditioning as an inhibitory procedure. Learning and Motivation, 1971, 2, 1-11.

Solomon, R. L., \& BRUSH, E. S. Experimentally derived conceptions of anxiety and aversion. In M. R. Jones (Ed.), Nebraska Symposium on Motivation, 1956, 4, 212-305.

TAYLOR, J. A. Level of conditioning and intensity of the adaptation stimulus. Journal of Experimental Psychology, 1956, 51, 127-130.

Usategui, R., Oliver, C., Vaudry, H., Lombardi, G., Rozenberg, I., \& MourRe, A. M. Immunoreactive $a$-MSH and ACTH levels in rat plasma and pituitary. Endocrinology, 1976, 98, 189-196.

Weiss, J. M., McEwen, B. S., Silva, M. T. A., \& Kalkut, M. F. Pituitary-adrenal influences on fear responding. Science, 1969, 163, 197-199.

Weiss, J. M., McEwen, B. S., Silva, M. T. A., \& Kalxut, M. F. Pituitary-adrenal alterations and fear responding. American Journal of Physiology, 1970, 218, 864-868.

(Received for publication July 11, 1978; revision accepted December 21, 1978.) 